\title{
EXPERIMENTAL ASSESMENT OF THE STRENGTH OF COACHES STRUCTURES AFTER COLLISION REPAIR
}

\author{
Enrique Alcalá Fazio \\ Bus and Coach Research unit Director, INSIA-UPM, Spain \\ David Rincón Dávila \\ Arturo Furones Crespo \\ Angel Luis Martín López \\ Bus and Coach Research unit Researcher, ETSI Industriales- UPM, Spain
}

\begin{abstract}
Vehicles repair after an accident and the quality assurance of the repair is a major safety issue. If the vehicle type category is M3, collective road transport vehicles, there is an additional concern due to their high number of occupants, the responsibility of third parties transport and the severity of some type of collisions such as rollovers.

Moreover it has to be considered that the high cost of these vehicles and the investment made on them by the transport companies makes it profitable to proceed to their repair after some accidents.
\end{abstract}

In this work it is quantified the loss of energy absorption capabilities of the structural steel profiles of rectangular hollow section used in the construction of these vehicles. The deformation energy has been measured by means of bending tests and calculating the bending moment vs bending angle curve. The load has been applied to reach 10, 15 and 20 permanent bending angles, representing those rollover structural deformations found on coach collisions of different severities. All test specimens have been straightened and bended up to 20 degrees some in the same bending direction as initial bend test and some in the opposite direction.

The results show a significant loss of strength of the profiles and the final influence on a repaired structure has been quantified modeling with a FEM model a standard Regulation ECE 66 of Geneva type approval test. It is then demonstrated how it should be defined requirements for repaired buses and coaches after their repair of structural damages in collisions.

\section{INTRODUCTION}

Rollovers are the most severe accidents of coaches and their consequences have required specific countermeasures to diminish the risks in case of accident. Being the most significate of these countermeasures the entry into force of UNECE Regulation 66 Revision 00 in December 12th 1986. Matolcsy (2007) concluded that R66.00 survival space concept and requirements were very effective (all casualty rate is $3-4$ times lower, the fatality rate is 
lower with one order (10 times) when the survival space remains intact). Since that date, several improvements to the Reg. 66 requirements have been established, and the most relevant of them has been the consideration in Revision 01 of the $50 \%$ of the mass of the passengers as consequence of the mandatory installation, and use, of the seat belts. The entry into force, in November 2005, of this revision has meant a 30\% average increase of energy absorption requirement for the superstructure (García et al. 2006). In this work, will be demonstrated that flexural bending and subsequent straightening of rectangular hollow sections can cause a structural weakening even higher than above-mentioned value (30\%).

The value of the analyzed vehicles (coaches) is high, and it is still high even after having experienced an accident if mechanical damages are not severe enough. For this reason, coaches that have been involved in an accident (e.g. rollover) are often repaired straightening their structures in repair benches. To date it has not been considered in any regulation, the establishment of repair or inspection criteria for structures of coaches after experiencing an accident.

In Spain, in 2014, a coach suffered an unfortunate accident with rollover and subsequent fall down a slope (14 deceased passengers). The same vehicle had experienced a previous lateral rollover accident in 2010. It should be noted that the preliminary accident did not cause severe structural deformations and, especially, that the severity of the second rollover accident make it impossible to establish relationships between the accident severity and the repair.

For all above-mentioned arguments, it has been considered a need to evaluate, experimentally in a first step, the loss of energy absorption capabilities of repaired rectangular hollow sections. The experimental results of the test plan has been applied to a model using Kecman (1983) rectangular hollow sections plastic hinges model to estimate the global lost of absorption capability of an R66.01 approved coach structure. In further steps of this research it will be assessed the best procedures and practices to proceed to coach structures repair.

\section{METHODOLOGY}

This research consists of the following two phases: The first one (phase I) is the experimental study of the behavior of the steel rectangular hollow sections by means of bending tests. Phase II has consisted in the application of the results obtained in the previous phase to a FEM analysis of the Reg 66.01 rollover test applied to a repaired coach structure.

\subsection{Experimental study of the steel profiles of rectangular hollow section by bending}




\section{tests (phase 1).}

The first step of the methodology is the determination of the characteristic Moment vs Angle curves and the absorbed energy by the profiles in bending tests applying the methodology proposed by García (1990). These tests were performed according the following procedure:

- STEP 1: the profile is bended to reach 5, 10 or 20 degrees of permanent deformation.

- STEP 2: the profile is straightened to its original geometry.

- STEP 3: the profile is bended up to 20 degrees in the same or the opposite direction than the first deformation.

Before those tests, a sample profile was tested by bending it to 40 degrees in order to have a pattern to compare to. After that, six profiles were tested as indicated before: two with 5 degrees of permanent first deformation, two with 10 and two with 20 degrees; in the three cases, one of every pair was bended in the same direction than the first deformation and the other in the opposite.

With the data of the displacement and load time histories of each test, the calculation of Moment - Angle and Absorbed energy curves can be carried out. Then, a coefficient of loss of absorption energy capability is estimated for the phase 2.

The characteristics of the tested profiles are presented in table 1:

\begin{tabular}{|c|c|c|c|}
\hline Material & $\begin{array}{c}\text { Height of hollow } \\
\text { section }\end{array}$ & $\begin{array}{c}\text { Width of hollow } \\
\text { section }\end{array}$ & $\begin{array}{c}\text { Thickness of hollow } \\
\text { section }\end{array}$ \\
\hline Steel S355 & $60 \mathrm{~mm}$ & $40 \mathrm{~mm}$ & $3 \mathrm{~mm}$ \\
\hline
\end{tabular}

Table 1 - Characteristics of tested profiles.

All test samples were manufactured using the same steel casting in order to eliminate the effects from variations in material properties. In figure 1, the absorbed energy by the profiles during the first deformation is shown, following the same curve. The behaviors of the profiles are, indeed, the same during the STEP 1 deformation process. 


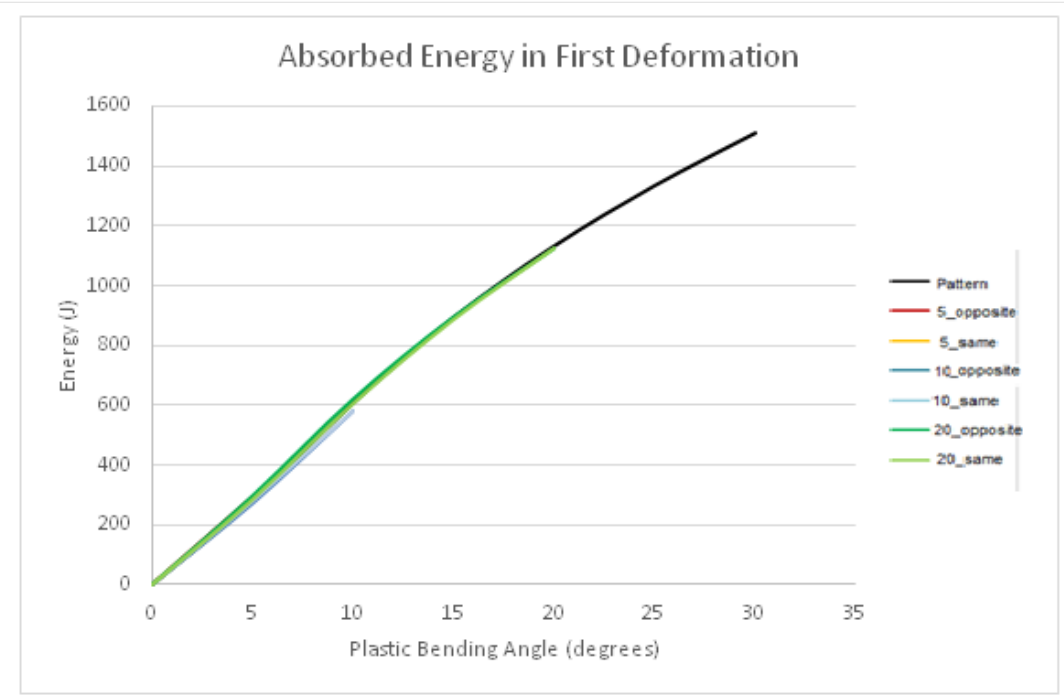

Fig. 1 - Absorbed plastic energy in STEP 1 deformation.

\subsection{Application to a repaired coach structure (phase 2).}

The last step of the methodology is to quantify the loss of energy absorption capability in a complete coach structure after repair. The different scenarios are proposed according to a repair from collisions of different severity; the collisions chosen are rollovers where the structure bends 5, 10 and 20 degrees.

In order to calculate the absorbed energy, the mechanical characteristics of the repaired structure are proportional to an undamaged structure, applying the coefficients obtained in phase 1 for the residuary absorption energy capability.

The calculation has been made with a FEM model according to the prescriptions defined at Regulation 66.01 Annex 7 - Quais-static loading test of body sections as an equivalent approval method - and with the characteristics used by Alcalá et al. (2010).

\section{RESULTS}

The next figures represent the Moment vs Bending angle curves of every profile tested, being:

- Blue curve: First deformation.

- Green curve: Repair.

- Red curve: Second deformation.

In every case, the curves are compared between both with the same first deformation bending angle but contrary direction in second deformation. 

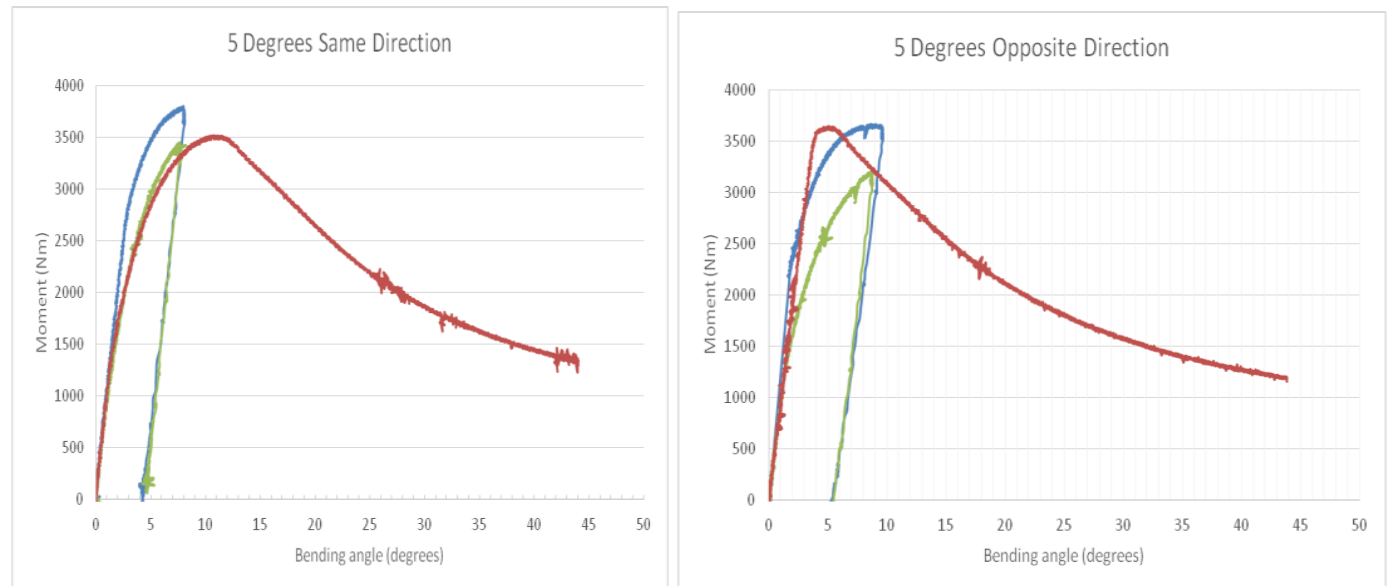

Fig. 2 - Moment - Bending angle. 5 degrees first deformation.
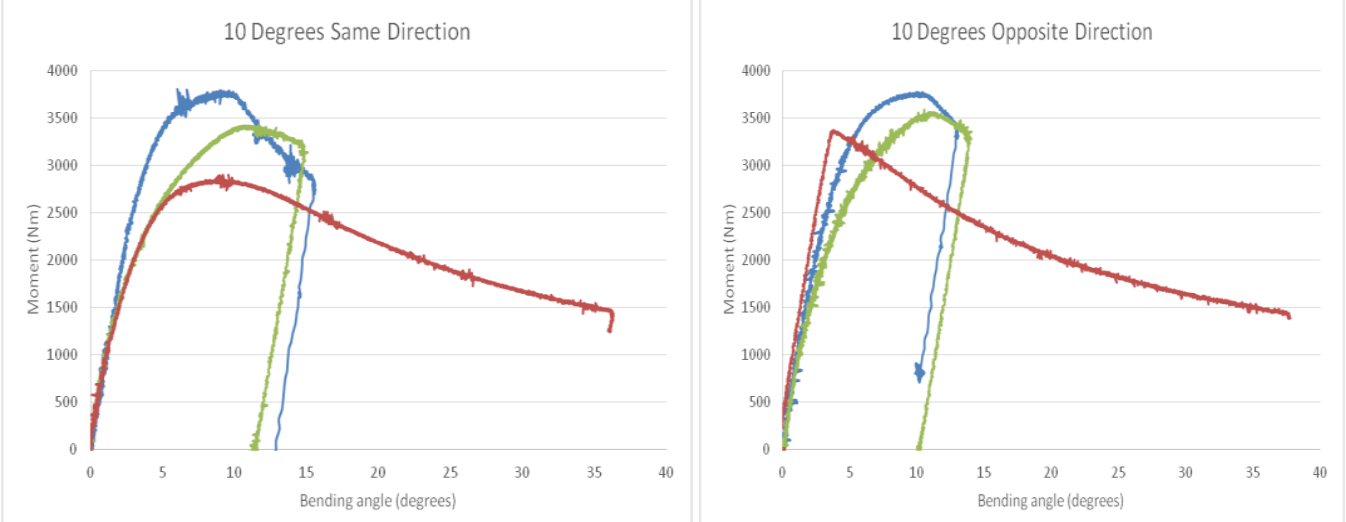

Fig. 3 - Moment - Bending angle. 10 degrees first deformation.
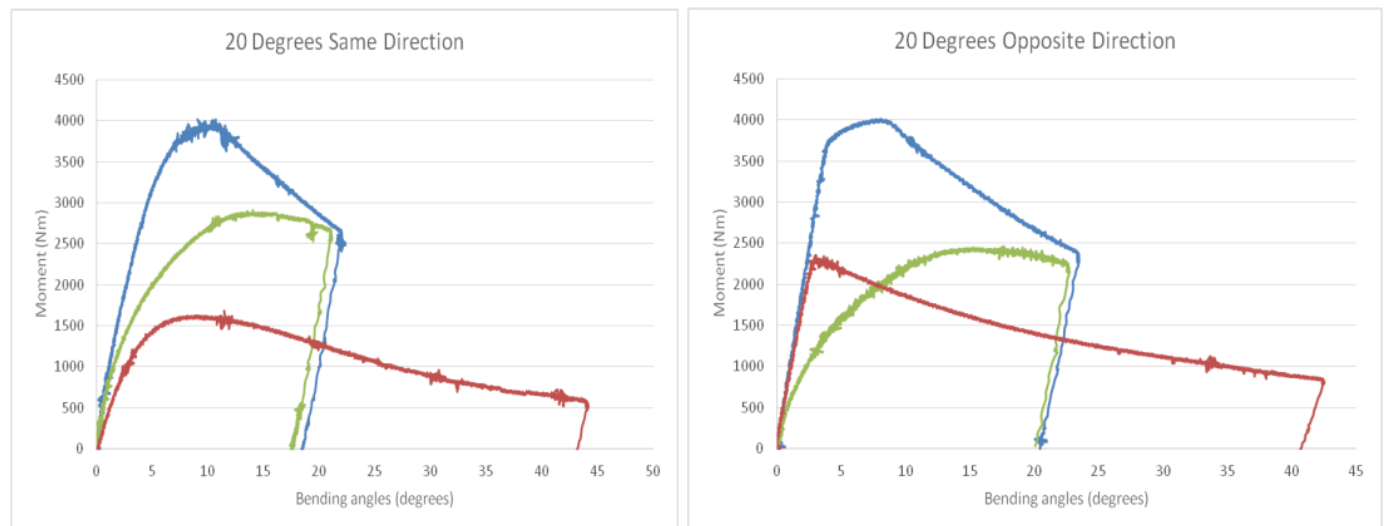

Fig. 4 - Moment - Bending angle. 20 degrees first deformation.

In order to understand the figures above, the next tables quantified the loss in energy absorption capability and maximum moment, which are the two values that give a better understanding of the behavior.

Table 1 compares the maximum moment reached in the second deformation with the one reached by the pattern sample, which is the same value of the maximum moment in the first deformation of all the samples. 


\begin{tabular}{|c|c|c|c|c|c|c|c|}
\hline Pattern & $\begin{array}{c}\mathbf{5}^{\mathbf{0}} \\
\text { Same } \\
\text { direction }\end{array}$ & $\begin{array}{c}\mathbf{5}^{\mathbf{0}} \\
\text { Opposite } \\
\text { direction }\end{array}$ & $\begin{array}{c}\mathbf{1 0}^{\mathbf{o}} \\
\text { Same } \\
\text { direction }\end{array}$ & $\begin{array}{c}\mathbf{1 0}^{\mathbf{o}} \\
\text { Opposite } \\
\text { direction }\end{array}$ & $\begin{array}{c}\mathbf{2 0}^{\mathbf{o}} \\
\text { Same } \\
\text { direction }\end{array}$ & $\begin{array}{c}\mathbf{2 0}^{\mathbf{o}} \\
\text { Opposite } \\
\text { direction }\end{array}$ \\
\hline $\begin{array}{c}\text { Maximum } \\
\text { Moment } \\
(\mathbf{N m})\end{array}$ & 4049 & 3580 & 3688 & 2834 & 3376 & 1186 & 2298 \\
\hline Percentage & 100 & 88 & 91 & 70 & 83 & 42 & 57 \\
\hline
\end{tabular}

Table 2 - Comparison of maximum moment.

Table 3 compares the absorbed energy in the second deformation at the point of 30 degrees in plastic region. The absorbed plastic energy during all the process is in figure 5.

\begin{tabular}{|c|c|c|c|c|c|c|c|}
\hline & Pattern & $\begin{array}{c}\mathbf{5}^{\mathbf{5}} \\
\text { Same } \\
\text { direction }\end{array}$ & $\begin{array}{c}\mathbf{5}^{\mathbf{0}} \\
\text { Opposite } \\
\text { direction }\end{array}$ & $\begin{array}{c}\mathbf{1 0}^{\mathbf{o}} \\
\text { Same } \\
\text { direction }\end{array}$ & $\begin{array}{c}\mathbf{1 0}^{\mathbf{o}} \\
\text { Opposite } \\
\text { direction }\end{array}$ & $\begin{array}{c}\mathbf{2 0}^{\mathbf{o}} \\
\text { Same } \\
\text { direction }\end{array}$ & $\begin{array}{c}\mathbf{2 0}^{\mathbf{o}} \\
\text { Opposite } \\
\text { direction }\end{array}$ \\
\hline $\begin{array}{c}\text { Absorbed } \\
\text { Energy } \\
(\mathbf{J})\end{array}$ & 1510 & 1324 & 1342 & 1159 & 1245 & 657 & 788 \\
\hline Percentage & 100 & 88 & 89 & 77 & 82 & 44 & 52 \\
\hline
\end{tabular}

Table 3 - Comparison of absorbed energy.

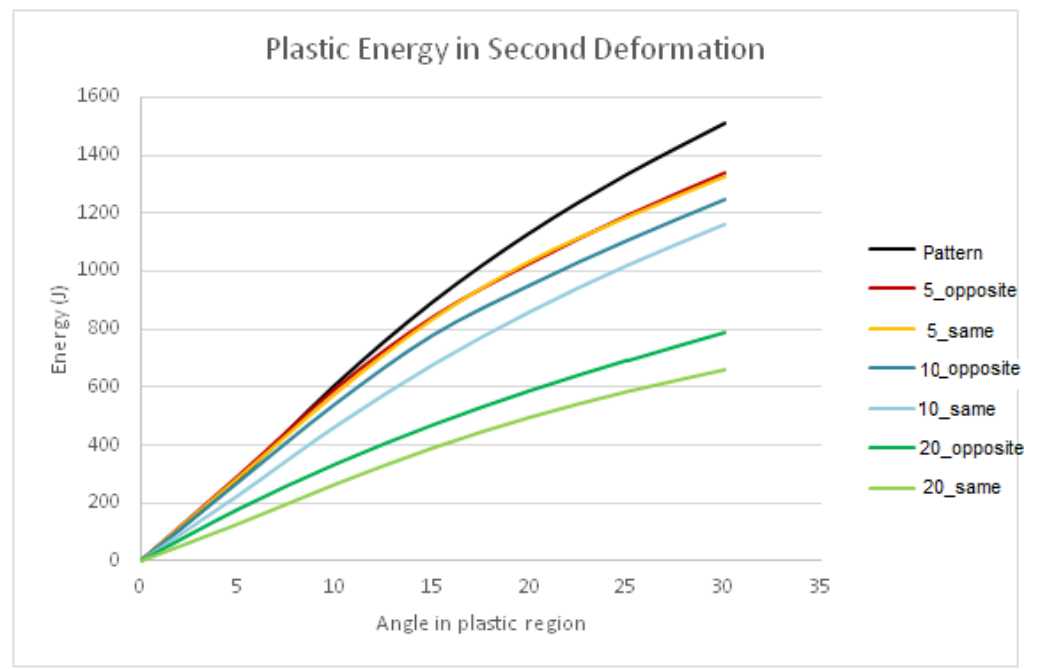

Fig. 5 - Absorbed plastic energy in second deformation.

The results of phase two, the application of the reduction coefficient from the tables above, into the characteristics of a FEM model of a coach structure can be summarized in the next table. It contains the absorbed energy by all the structure after the repair of a previous bending of 5, 10 and 20 degrees of bending angle. The values for an initial deformation of 0 degrees belong to the structure with no damage. 


\begin{tabular}{|c|c|c|c|c|}
\hline $\begin{array}{c}\text { Initial } \\
\text { deformation } \\
\text { (degrees) }\end{array}$ & $\mathbf{0}$ & $\mathbf{5}$ & $\mathbf{1 0}$ & $\mathbf{2 0}$ \\
\hline $\begin{array}{c}\text { Absorbed } \\
\text { energy (J) }\end{array}$ & 104563 & 94437 & 90811 & 51801 \\
\hline Percentage (\%) & 100,0 & 90,3 & 86,8 & 49,5 \\
\hline
\end{tabular}

Table 4 - Comparison of absorbed energy in a repair coach structure.

According to table 4, repaired coach structures should not be treated as an original, or undamaged, structure.

\section{DISCUSSION}

The results show a loss of strength in the profiles tested during and after the repair compared to their initial characteristics. This loss is greater as the bending deformation angles are increasing, reaching in the 20 degrees deformation samples a loss of 50 per cent.

This loss in energy absorption can be explained with the Moment vs bending angle curves, comparing the first and second deformation curves. In the second one, the maximum moment is lower, reducing the area beneath the curve and so the energy as well. However, the slope of the curve in the plastic region (after the maximum moment), is minor in the second deformation.

Another point to highlight is the different behavior depending on the direction of the second deformation. If the second deformation is in the opposite direction of the first one, the maximum moment does not decrease as much as it does when the deformation is in the same direction; so, the energy absorption capability depends not only on the bending angles but on the direction of the bending.

When the rollover of a coach occurs, the bending angles can reach any value depending on the severity of the collision. Two values that can be considered as an approximation to understand the issue are 15 and 30 degrees, which are the bending angles when de deformation occurs at floor and window height, respectively.

As the table 3 shows, the absorption energy capability of a repaired coach structure can be highly reduced when 10 and 20 degrees are reached in a rollover.

It is major issue then, to define the requirements of a repaired coach structure. 


\section{CONCLUSSIONS}

It has been measured the loss of energy absorption capability of rectangular hollow sections after experimenting flexural bending permanent deformation and a subsequent repair, showing a significant loss above10 degrees of plastic deformation.

The application of the measured loss of capability of the profiles to a standard coach structure has shown a relevant loss of rollover crashworthiness indicating that there is a need to define the procedures of reparation as well as those of post-repair inspections.

Current analytical models, representative of the flexural bending behavior of rectangular hollow sections, are not adequate to represent the absorption capability of repaired by straightening profiles.

\section{AKNOWLEDGMENTS}

This research has been held with the support of the Madrid Community Council of Ediucation, Youth and Sport who funded the project 'SEGuridad de los Vehículos AUTOmóviles, por un TRansporte Inteligente, Eficiente y Seguro' (SEGVAUTO-TRIESCM) (P2013/MIT-2713) in the 2008-2011 National Research Program

\section{REFERENCES.}

Alcalá Fazio, Enrique; Aparicio Izquierdo, Francisco; Grimaldi Pastoril, Rocío y Martín López, Ángel Luis (2010). Aplicación de técnicas de ensayo virtual a ensayos de vuelco de superestructuras de Autobuses y autocares. "IX Congreso de Ingeniería del Transporte, CIT 2010", 07/07/2010 - 09/07/2010, Madrid, España.

García, A. (1990) Estudio teórico y experimental del comportamiento de las superestructuras de vehículos de grandes dimensiones para el transporte de pasajeros bajo la acción de vuelco lateral. PhD Thesis.

García, A; Vicente Corral, T; Sánchez Lozano, M. (2006). Impact of the use of safety belts on the structural requirements Ander rollover of coaches. International Journal of Heavy Vehicle Systems. ISSN (Online) 1741-5152 (Print) 1744-232X. Volumen 13, Issue 3. pp 163169.

Dušan Kecman†. (1983). Bending collapse of rectangular and square section tubes. International Journal of Mechanical Sciences. Volume 25, Issues 9-10. pp 623-636. Special Issue Structural Crashworthiness Conference

Mátyás Matolcsy. (2007). The severity of bus rollover accidents. 20th International Technical Conference on the Enhanced Safety of Vehicles (ESV) Paper Number: 070989.

UNECE Regulation No 6600 Series (1986) of the United Nations Economic Commission for Europe - uniform technical prescriptions concerning the approval of large passenger vehicles with regard to the strength of their superstructure. 
UNECE Regulation No 6601 Series (2005) of the United Nations Economic Commission for Europe - uniform technical prescriptions concerning the approval of large passenger vehicles with regard to the strength of their superstructure. 